\title{
The cannabinoids: An overview. Therapeutic implications in vomiting and nausea after cancer chemotherapy, in appetite promotion, in multiple sclerosis and in neuroprotection
}

\author{
R Mechoulam PhD*, L Hanuš PhD
}

R Mechoulam, L Hanuš.

The cannabinoids: An overview. Therapeutic implications in vomiting and nausea after cancer chemotherapy, in appetite promotion, in multiple sclerosis and in neuroprotection. Pain Res Manage 2001;6(2):67-73.

The present paper describes the historical use of cannabis, starting with its use in Assyria and China. Recent advances in the understanding of the molecular basis of cannabis action are explained, including the identification of the cannabinoid receptors $\mathrm{CB}_{1}$ and $\mathrm{CB}_{2}$, as well as the isolation of endogenous cannabinoids from the brain and periphery. The use of delta ${ }^{9}$-tetrahydrocannabinol as an antivomiting and antinausea drug for cancer chemotherapy, and as an appetite-enhancing agent is described. Clinical work in multiple sclerosis, which may lead to the approval of tetrahydro- cannabinol as a drug for this condition, is presented. Preclinical and clinical investigations with cannabidiol, a nonpsychotropic cannabis constituent, are also described. Recent work with cannabidiol in animal models of rheumatoid arthritis may lead to clinical investigations. A synthetic cannabinoid, HU-211 (Dexanabinol), is in advanced clinical stages of investigation as a neuroprotectant in head trauma. The above clinical approaches may ultimately lead to the realization that cannabinoids are valuable clinical drugs in numerous fields.

Key Words: Anandamide; Cannabidiol; Endocannabinoids; HU-211; Tetrohydrocannabinol

Pour le résumé, voir page suivante

Hebrew University, Jerusalem, Israel

Correspondence: Professor R Mechoulam, Hebrew University, Medical Faculty, Ein Kerem Campus, Jerusalem 91120, Israel.

Telephone +972-2-6758634, fax +972-2-6410740, e-mail Mechou@cc.huji.ac.il

*Dr Mechoulam is the Lionel Jacobson Professor of Medicinal Chemistry at the Hebrew University of Jerusalem. Dr Mechoulam has been working on cannabinoid chemistry (he coined the term) since the early 1960s at which time he was Junior Scientist at the Weizmann Institute. Dr Mechoulam's primary interest has been in the chemistry and biological activity of natural products and synthetic drugs. Throughout this time Dr Mechoulam has made major contributions to the field of cannabinoid research. His laboratory was the first to synthesize tetrahydrocannabinol, the major psychoactive marijuana constituent; they then went on to isolate and elucidate the structures of most members of the cannabinoid group of compounds in the cannabis plant. Later, he and colleagues identified the metabolites and more recently discovered the endogenous cannabinoids anandamide and 2-arachidonylglycerol (2-AG). These findings have profoundly advanced the understanding of cannabinoid systems. Dr Mechoulam has received numerous honours and awards for his outstanding contributions to the field and is Past President of the International Cannabinoid Research Society. 


\section{Les dérivés du cannabis : vue d'ensemble. Leurs effets thérapeutiques sur les vomisse- ments et les nausées après la chimiothérapie pour cancer, sur l'appétit dans la sclérose en plaques et sur la neuroprotection}

RÉSUMÉ : Cet article brosse l'histoire du cannabis utilisé à des fins thérapeutiques depuis l'époque des Assyriens et de la Chine ancienne. L'approfondissement de nos connaissances sur les bases moléculaires de l'action du cannabis y sont expliquées, notamment l'identification des récepteurs $\mathrm{CB} 1$ et $\mathrm{CB} 2$ des dérivés du cannabis, de même que l'identification de cannabis endogène au niveau du cerveau et du système périphérique. On y décrit également l'utilisation du delta9 ${ }^{9}$-tétrahydrocannabinol comme antiémétique chez les patients sous chimiothérapie et comme agent stimulant l'appétit. On présente en outre des travaux cliniques sur la sclérose en plaques qui pourraient conduire à l'approbation du tétrahydrocannabinol pour cette maladie. Des recherches précliniques et cliniques sur le cannabinol, un ingrédient non psychotrope du cannabis, sont en outre décrites. De récents travaux sur le cannabidiol dans des modèles animaux de polyarthrite rhumatoïde pourraient aussi donner le coup d'envoi à des recherches cliniques. Le dérivé synthétique du cannabis HU-211 (Dexanabinol) fait l'objet de recherches cliniques avancées en tant que neuroprotecteur lors des traumatismes cérébraux. Les approches cliniques ci-dessus pourraient éventuellement conduire à la création de dérivés du cannabis comme médicaments cliniques dans de nombreux domaines.
$C^{\prime}$ Mannabis sativa $L$ was one of the first plants to be used by man for fibre, food and medicine, and in social and religious rituals. The best historical evidence for the use of cannabis in medicine comes from China and Assyria. Cannabis is mentioned in the medical classic known as Shen Nung Ben Ts'ao (first century AD), but it was probably already in use by the Yellow Emperor Huang Ti (circa 2600 BC) (1). Cannabis in wine was used as an anesthetic in major operations circa the third century AD (2). Because cannabis is not a potent analgesic, one can only assume that large stupefying doses were administered.

The Chinese were also aware of the dual nature of cannabis. A medieval herbal states:

Ma-fen is used for waste diseases and injuries; it clears blood and cools temperature ... it undoes rheumatism; it discharges pus. If taken in excess it produces hallucinations and a staggering gait. If taken over a long term it causes one to communicate with spirits and lightens one's body. (3)

Can this statement on ancient Chinese therapy be compared with the modern view of the effects of cannabis? Tetrahydrocannabinol (THC) enhance appetite in acquired immune deficiency syndrome (AIDS) patients (4), which can be equated with ancient Ma-fen use for waste diseases and injuries; cannabinoids also provide neuroprotection (5) and are well known to reduce temperature (6). A recent paper described the effects of cannabidiol (CBD), a major cannabis constituent, in collagen-induced arthritis in mice (7), which obviously fits with the ancient use of cannabis for 'rheumatism'. A 'staggering gait' is certainly noted after heavy cannabis use. However, it is doubted that 'communication with spirits' with the help of cannabis is common nowadays.

The Assyrian medical legacy includes fragments of cuneiform plant lists, most of them from the era of Ashurbanipal (626 BC). Several names for cannabis were used, which were mostly associated with the term 'azallu' (to spin). The Sumerians used a similar name, azalla, indicating a very ancient origin. Gan-zi-gun-nu is another name for cannabis used by the Assyrians. It means 'the drug that takes away the mind'. Cannabis was used medically in several ways. Externally, it was used as a constituent of various ointments for swelling and bruises. Cannabis fumes were a drug for the 'poison of all limbs' (presumably arthritis). Azallu, either as a drink or in food, was prescribed for the depression of spirits, for impotence and to 'annul witchcraft' (8).

Over millenia, cannabis continued to be used as a drug, mostly for pain, inflammation, epilepsy and various other neurological diseases $(1,9)$. In the early 19th century, O'Shaugnessy (10) demonstrated that many of the therapeutic uses of cannabis in Indian medicine (such as for cramps, convulsions in children, migraines, inflammation, neuralgia and tetanus) were well founded. His reports accepted 'Indian hemp' as a therapeutic agent, first in England, and later in other European countries and North America. Indeed, Reynolds (11), a noted English physician, stated that "Indian hemp when pure and administered carefully is one of the most valuable medicines we possess".

Around the turn of the century, the medical use of cannabis declined, because reproducible clinical effects could not be obtained. At the time, the active constituent in cannabis had not been isolated in pure form. Instead, plant extracts were generally used, and these were known to deteriorate rapidly, thus accounting for the nonreproducible effects.

Work on the medicinal use of cannabis was resumed in 1964 when the major, and essentially only, psychoactive constitutent of cannabis, $\Delta^{9}-\mathrm{THC}$, was isolated in pure form and its structure was elucidated (12). Simple synthetic routes became available, and the pharmacological activity of numerous cannabinoids was examined in animals and humans (13). For about two decades, thousands of papers appeared on the chemical, pharmacological, metabolic and clinical aspects of cannabinoid action. However, its mechanism of action remained an enigma until the past few years.

The present selective review covers recent advances in the understanding of the mechanism of cannabinoid action, followed by a summary of research on cannabinoids in the prevention of vomiting and nausea after chemotherapy, as well as in appetite promotion, multiple sclerosis (MS) and neuroprotection. Pain research is not discussed, because it is the topic of an accompanying article. 


\section{MOLECULAR BASIS OF CANNABINOID ACTION}

During the 1970s and early 1980s, it was generally assumed that the high lipophilicity of the cannabinoids was the cause of much of their pharmacological effects. The possibility that THC acts through specific receptors was dismissed due to the lack of stereospecificity of cannabinoid action $(13,14)$. In the mid-1980s, several groups showed that the presumed lack of stereospecificity was due to synthetic problems, and that in actuality, cannabinoid activity is highly stereoselective $(13,14)$.

The first crucial step in elucidating the molecular basis of cannabinoid action was achieved in 1988. A radiolabelled, potent synthetic cannabinoid was found to bind to brain membranes in a highly specific and selective manner, exhibiting features that are characteristic of receptor binding (15). In several animal behavioural tests assessing sedation, body temperature and analgesia, a strong correlation was found between the pharmacological potencies of cannabinoids and their affinity for the cannabinoid brain receptor. It was also shown that cannabinoid ligands inhibit the activity of adenylate cyclase and N-type voltage-dependent calcium channels, and that these signal transduction pathways are mediated through the inhibitory guanosine triphosphate-binding protein $\mathrm{G}_{\mathrm{i}} / \mathrm{G}_{\mathrm{o}}(14)$. Within a short time, the receptor (now named $\mathrm{CB}_{1}$ ) was cloned from the rat and human brain (16). It was shown to belong to the seven transmembrane domain receptor family, which mediates its activity through GTP-binding proteins.

In addition to their effects in the central nervous system, cannabinoid ligands have immunomodulatory effects. Indeed, a peripheral cannabinoid receptor $\left(\mathrm{CB}_{2}\right)$ has been cloned from a human promyelocytic leukemic line (HL60) (17). This receptor was shown to be only partially homologous with the brain receptor. It is present in macrophages and in the marginal zone of the spleen (18), but not in the brain (17).

The existence of cannabinoid receptors suggested the presence of endogenous ligands. To look for such ligands, a specific, highly potent, radiolabelled probe - $\left[{ }^{3} \mathrm{H}\right] \mathrm{HU}-243-$ was prepared (19). Porcine brain fractions were found to compete with this probe in binding to cannabinoid receptors. Chromatography of such brain fractions led to the identification of a family of unsaturated fatty acid ethanolamides with THC-like activity $(20,21)$.

Although some ethanolamides of fatty acids have long been known to be endogenous constituents of animal tissues (22), the discovery that they are endogenous cannabinoids was unexpected. So far, three active acylethanolamides have been identified in the brain. They are the ethanolamides of arachidonic acid (20), docosatetraenoic acid and dihomogamma-linolenic acid (21). The term 'anandamide' refers to arachidonoyl ethanolamide. Most of the recent pharmacological and biochemical work reported so far has been with this compound $(13,20,23,24)$.

The existence of a peripheral cannabinoid receptor $\left(\mathrm{CB}_{2}\right)$, found mostly in cells of the immune system, led us to investigate the possibility that peripheral cannabinoid ligands, distinct from the anandamides, are present in such organs. Following the procedures described for the isola- tion of anandamide, a lipid-soluble constituent from canine gut was isolated (25). Its structure was elucidated as 2-arachidonoylglycerol (2-AG) by mass spectrometry and direct comparison with a synthetic sample. 2-AG binds to membranes from African green monkey COS cells transiently transfected with expression plasmids containing DNA (having $\mathrm{CB}_{1}$ or $\mathrm{CB}_{2}$ receptors). Sugiura et al (26) later identified $2-A G$ in the brain. In the pancreas and spleen, 2-AG is accompanied by additional 2-acyl-glycerols, such as 2-linoleoylglycerol, 2-palmitoylglycerol and 2-myristoylglycerol, which considerably potentiate its binding to $\mathrm{CB}_{1}$ and $\mathrm{CB}_{2}$, as well as its in vivo activity (27). Thus, to date, two types of endogenous cannabinoid ligands are known to exist: amides (anandamide) and esters (2-AG). Neither of these ligands is stable in vivo, because a specific endocannabinoid amidaseesterase (fatty acid amide hydrolase) is present in tissues (28) and causes hydrolysis of these ligands. The biochemistry and pharmacology of anandamide have been the topics of hundreds of publications and have been extensively reviewed $(20,23,24,28)$. 2-AG has not been investigated to the same extent, probably because of its instability.

Neither anandamide nor 2-AG has undergone the toxicological tests needed before human trials can begin; hence, nothing is known of their effects in humans. However, the identification of the endocannabinoid system has facilitated a better understanding of the effects of the plant cannabinoids and their derivatives. Indeed, much of the recent pharmacological work on the plant-derived cannabinoids has been closely associated with the endocannabinoid system. The advances made in elucidating the molecular basis of cannabinoid action have led to a renewed interest in the medicinal properties of the natural and synthetic cannabinoids.

\section{THC AS AN ANTIEMETIC DRUG AND APPETITE PROMOTER}

A long list of potential therapeutic uses for THC has been recorded over the course of many years, based on its analgesic, bronchodilatory, antiemetic, anticonvulsant and antiinflammatory effects, as well as its ability to reduce intraocular pressure and alleviate some neurological conditions (seizure disorders, spasticity associated with spinal cord injuries and MS). Academic and industrial laboratories examined numerous natural and synthetic cannabinoids to obtain cannabinoids in which the desirable effects were separated from the undesirable typical psychotropic action (29). The results have been disappointing. The level of psychotropic activity almost always paralleled that of the potential therapeutic effects. Nevertheless, THC was approved by regulatory authorities in several countries, including the United States, for use in two medical conditions: for nausea and vomiting due to anticancer treatment, and in appetite promotion (4). A psychotropic cannabinoid, nabilone, which parallels THC in most of its actions but is considerably more potent, is used in the United Kingdom and in Switzerland (30).

The antiemetic activity of cannabinoids (31), the mechanism of which is still obscure, apparently is not mediated via the cannabinoid receptors. Hence, noncannabimimetic 
cannabinoids may prevent emesis without causing THCtype effects. HU-211 (see below) is indeed a potent antivomiting agent in pigeons, although it does not bind to the cannabinoid receptors (32).

We have noted that, in mice, the response to THC develops gradually and does not reach maximal potency until adulthood, possibly due to the gradual development of the receptors. THC administered to mice shortly after birth exhibits essentially no activity (33). We assumed that if this observation was relevant in humans, young children who are administered THC for preventing the side effects of cancer chemotherapy would not experience THC-type effects, while the antiemetic potential might be preserved. $\Delta^{8}$-THC was chosen instead of the marketed $\Delta^{9}$-THC because it is less psychotropic, much less expensive to produce and is much more stable than $\Delta^{9}$-THC. A clinical trial was started at a low dose $\left(5 \mathrm{mg} / \mathrm{m}^{2}\right)$, which in some adults is enough to cause typical marijuana effects and anxiety. At this or higher doses, no psychotropic effects were seen in children. Vomiting and nausea caused by cancer chemotherapy were completely eliminated (34).

One of the symptoms of AIDS is weight loss. Many patients smoke marijuana because it is an appetite stimulant. This has been supported by several clinical studies. In one such study, the effects of $\Delta^{9}$-THC (also known as dronabinol) (2.5 $\mathrm{mg}$ bid) on appetite, weight and nausea were examined in 139 patients with AIDS over a six-week period (35). After four weeks, the patients' weights were stable in the treated patients but lower in the placebo recipients. The data indicated that dronabinol caused increased appetite in about onethird of the patients. The authors of this study concluded that:

\section{Dronabinol is a safe and effective treatment for anorexia in patients with weight loss due to AIDS. By improving appetite and mood, decreasing nausea, and stabilizing weight, dronabinol may significantly improve the quality of life of patients infected with HIV. (35)}

\section{THC IN MS}

As mentioned above, the Assyrians apparently used cannabis for neurological diseases. Azallu was a drug against the 'poison of all limbs' and against 'arimtu', which was probably a neurological disease of the legs. Was one of these two disorders MS?

MS is a disorder that attacks the myelin sheath of nerve fibres. The cause is unknown, but it is presumably an autoimmune disease triggered by an environmental factor. The disease usually progresses slowly, with exacerbations and remissions over many years. The symptoms vary and include tiredness, spasticity, leg weakness, inability to walk, lack of balance, muscle pain, tremors, vision problems, urinary hesitancy and incontinence, slurred speech and memory loss. A variety of partially effective drug treatments are in use. Corticosteroids are the cornerstone of therapy. However, their efficacy is limited, and chronic use entails considerable risk. Carbamazepine and phenytoin are used for pain, and numerous other drugs are employed for specific symptoms. Current therapeutic strategies, however, are far from ideal. The lack of an efficient drug treatment has led patients to search for additional therapies, one of which is cannabis. Cannabis is used currently by MS patients, although it is not an approved drug (36).

Several animal studies involving cannabinoids have been described using an experimental model of MS. This model, known as experimental autoimmune encephalomyelitis (EAE), is based on the generalized atonia, quadriplegia and death of rats or guinea pigs administered central nervous system tissue or myelin basic protein. The animals are observed over a period of several weeks. In one of these studies, Lyman et al (37) noted that $\Delta^{9}$-THC decreased EAE inflammation, led to much reduced neurological effects and delayed the time of the appearance of the MS effects. In a second study, $\Delta^{8}$-THC was used, and again, the drug significantly reduced the incidence and severity of neurological deficits in two strains of rats (38). Serum corticosterone levels were elevated twofold in rats with EAE that were chronically treated with $\Delta^{8}$-THC. These results suggest that suppression of EAE by cannabinoids may be related to their effect on corticosterone secretion (38).

More recently, Baker et al (39) researched the actions of cannabinoids using a related model of MS known as chronic relapsing experimental allergic encephalomyelitis. After chronic relapsing experimental allergic encephalomyelitis induction by sensitization to myelin antigens, mice develop spasticity and tremors. Baker et al (39) showed that several $\mathrm{CB}_{1}$ agonists and $\mathrm{CB}_{2}$ agonist quantitatively ameliorated both tremors and spasticity in diseased mice. The exacerbation of these signs after antagonism of the $\mathrm{CB}_{1}$ and $\mathrm{CB}_{2}$ receptors using the $\mathrm{CB}_{1}$ and $\mathrm{CB}_{2}$ antagonists (SR141616A and SR144528, respectively) showed that the endogenous cannabinoid system may be tonically active in the control of tremor and spasticity. The authors suggested that these observations provide a rationale for the therapeutic use of cannabis in the control of symptoms of MS.

Several small scale clinical trials have been conducted. In one such typical double-blind trial, a group of nine patients were administered up to $10 \mathrm{mg}$ of $\Delta^{9}$-THC (40). Some patients felt that they were able to walk better. The authors measured deep tendon reflexes, muscular resistance to leg stretching and abnormal reflexes, and found improvements in these parameters. In a more recent report, Brenneisen et al (41) orally administered $\Delta^{9}$-THC (10 to $15 \mathrm{mg}$ ) to two patients and compared its effects with those of $\Delta^{9}$-THC hemisuccinate administered by suppositories. Both treatments reduced spasticity and rigidity, and improved walking in objective measurements.

Consroe et al (36) reported and analyzed the answers to a questionnaire mailed to MS patients who use cannabis. Most of the patients reported much improvement after cannabis use in spasticity, sleep onset, awakening at night, leg pain at night and tremors. The patients also reported improvement in anxiety, depression and spasticity when awaking in the morning and on walking. There was only 
minor improvement in memory loss, fecal incontinence and constipation. This difference in reported symptom improvement may indicate that the effects are not placebo effects.

A report (42) by the British Medical Association concluded that:

\section{Cannabinoids may have a potential use for patients with spastic neurological disorders such as MS and spinal cord injury. Such patients often have distressing symptoms, which are not well controlled with available drugs. Carefully controlled trials of cannabinoids in patients with chronic spastic disorders which have not responded to other drugs are indicated. Such trials merit a high priority.}

Comparable conclusions have been reached by a House of Lords Committee in the United Kingdom and in a report by the United States Academy of Medicine. Perhaps the Assyrians were justified in using cannabis as a drug against neurological disorders.

\section{CBD}

The main side effects of THC and synthetic cannabinoids, such as nabilone and levonanthradol, are their psychoactive properties. It is, therefore, surprising that $\mathrm{CBD}$, the major nonpsychotropic cannabis constituent, has received only scant attention. $\mathrm{CBD}$ does not bind to the $\mathrm{CB}_{1}$ receptor (unpublished data) and is inactive in the tetrad of effects in mice (analgesia, lowered temperature, reduced locomotion in an open field test and catalepsy), which is typical of the psychoactive cannabinoids (43; unpublished data).

The first group to investigate the action of CBD on seizures was Carlini et al (44). They published a series of papers in which it was shown that CBD had a potent anticonvulsant effect in several assays. This was confirmed and expanded by several additional groups using various procedures (45). On the basis of laboratory data in animals, CBD appeared to have good potential as an anticonvulsant. In animals, the protective index for CBD was similar to that for pentobarbital.

This preclinical work led to a double-blind clinical trial (46). After a successful phase 1 study in which no side effects were noted, a phase 2 trial was initiated. In this study, 15 patients suffering from secondary generalized epilepsy with temporal focus were randomly divided into two groups. Each patient received up to $300 \mathrm{mg}$ daily of either CBD or placebo. The drugs were administered for as long as four-and-a-half months. Clinical and laboratory examinations, electroencephalograms and electrocardiograms were performed at 15or 30-day intervals. A drawback in this trial was that, for ethical reasons, the patients continued to take the antiepileptic drugs prescribed before the experiment, although these drugs no longer controlled the signs of the disease. No signs of toxicity or serious side effects were detected on examination. Four of eight CBD subjects remained almost completely free of convulsions throughout the experiment, and three other patients demonstrated partial improvement in their clinical condition. CBD was ineffective in one patient. The clinical condition of seven placebo patients remained unchanged, whereas the condition of one patient clearly improved.

No further clinical work on epilepsy has been reported. Probably, this is mainly due to financial considerations, such as the lack of patent protection. From the point of view of the pharmaceutical investigator, the high doses required and the set-up of the clinical trial in which CBD was administered together with other drugs, may have deterred further clinical work.

CBD also has been the object of investigations in other areas. There are a few reports that have been written concerning the in vitro effects of CBD on immune cells, including the modulation of the cytokine interleukin-1 by human peripheral blood mononuclear cells $(47,48)$ and the suppression of chemokine production by a human B cell line (49). These potentially anti-inflammatory properties of $\mathrm{CBD}$, together with the lack of a psychotropic effect and low toxicity, led to an investigation on the effect of CBD in collagen-induced arthritis (CIA) (7). It was found that intraperitoneal CBD blocked lipopolysaccharide-induced serum tumour necrosis factor (TNF)- $\alpha$ production in mice. TNF- $\alpha$ is a proinflammatory cytokine known to be a major mediator of arthritis. However, there was no suppression of TNF release by arthritic synovial cells when CBD was added in vitro (7). This discrepancy between in vivo and in vitro results suggests that the TNF suppression may be mediated by an active metabolite of CBD. Subsequently, the activity of CBD was investigated in murine CIA. CIA was elicited by immunizing mice with type II collagen in complete Freund's adjuvant. The type II collagen was either bovine or murine, resulting in classical acute CIA or in chronic relapsing CIA, respectively. CBD was administered after the onset of clinical symptoms, and in both models of arthritis, the treatment effectively blocked the progression of arthritis. CBD was equally effective when administered intraperitoneally or orally. The dose dependency showed a bell-shaped curve, with an optimal effect at $5 \mathrm{mg} / \mathrm{kg} /$ day intraperitoneally or $25 \mathrm{mg} / \mathrm{kg} /$ day orally. Clinical improvement was associated with protection of the joints against severe damage. These data show that CBD, through its combined immunosuppressive and anti-inflammatory actions, has a potent antiarthritic effect in CIA (7).

CBD also possesses inherent anxiolytic properties. In an animal model for anxiety, the elevated plus-maze test, it was shown that CBD is an antianxiety agent, slightly less potent than diazepam (50). Likewise, in a human trial, CBD showed anxiolytic effects (51). CBD also antagonizes the decrease in body temperature, and the increase in heart rate and respiration produced by $\mathrm{THC}(6)$. It attenuates the psychotomimetic and anxiogenic effects induced by high doses of THC in humans (52). These effects are not based on pharmacological interactions (53), and because CBD does not bind to the $\mathrm{CB}_{1}$ receptor, they are not based on competitive antagonism. It is possible that CBD binds to a yet unrecognized receptor.

CBD has also been found to be active in animal models predictive of antipsychotic activity. Leweke et al (54) showed that $\mathrm{CBD}$ reduces the binocular depth inversion effect, which 
is a human model of impaired perception during psychotic states. One case was reported in which a patient experienced an antipsychotic effect from CBD use comparable with that from haloperidol use (55). The authors concluded that CBD may have an 'atypical antipsychotic profile'.

In summary, $\mathrm{CBD}$ has been shown to produce a variety of seemingly unrelated effects - anti-inflammatory, antianxiety and antipsychotic - the molecular basis of which is unknown. Similarly, the basis of the blocking action of THC is not known.

\section{HU-211}

The observation that the effects of cannabinoids are not exclusively mediated by the known $\mathrm{CB} 1$ and $\mathrm{CB} 2$ receptors is strongly supported by work with HU-211 (Dexanabinol; Pharmos, USA). This compound is the nonpsychotropic enantiomer (mirror image) of one of the most potent synthetic cannabinoids prepared so far - namely, HU-210 (56). HU-211 was found to be completely inactive in a series studying typical in vivo cannabinoid effects (56). Unexpectedly, HU-211 was found to show numerous noncannabinoid effects. Thus, it blocked the uptake of radioactive calcium ions and protected neurons from glutamate neurotoxicity mediated by $N$-methyl-D-aspartate (NMDA) receptors (57-59). These studies suggest that HU-211 activity is mediated by interaction at sites located within the NMDA receptor-linked ion channels. Indeed, HU-211 displaces NMDA from its specific glutamate binding site $(59,60)$. It is also an effective scavenger of peroxy radicals, which cause oxidative damage, and strongly inhibits the release of TNF- $\alpha$ (60). This promising combination of effects led to extensive in vivo studies. The initial model chosen was closed head injury in rats. In this model, following a primary, mechanical trauma, a cascade of events is triggered leading to secondary brain damage: brain edema, disruption of the blood-brain barrier, focal or distant ischemia, vasospasm and release of numerous toxic mediators $(60,61)$. HU-211 was administered intravenously to experimental animals 1 to $4 \mathrm{~h}$ after injury. The parameters typically assessed to define the extent of damage and to evaluate the neuroprotective effect of the drug were: edema (water content), blood-brain barrier integrity, clinical status and memory. These parameters were evaluated for 30 days. HU-211 was very effective at improving cognitive and motor function recovery during the entire evaluation period. It also reduced blood-brain barrier breakdown and attenuated the development of cerebral edema in the traumatized hemisphere. Hippocampal cells (which are associated with memory) were also protected by HU-211 treatment (60). It was concluded that HU-211 is an effective cerebroprotective agent, even when administered up to $4 \mathrm{~h}$ after the closed head injury. The beneficial effect obtained from even a single dose is long lasting, and ameliorates the impairment of both motor and cognitive functions following closed head injury.

Other models of neuroprotection were also investigated. Biegon and Bar-Joseph (61) found that in Mongolian gerbils who had a bilateral carotid occlusion, there was significant cell survival in the hippocampal region in animals that had received HU-211 (60). In a permanent middle cerebral artery occlusion model of cerebral ischemia, HU-211 was also a potent protective agent (62).

These positive preclinical studies have led to several clinical trials. After a toxicological study was completed in two species, a phase 1 clinical trial was undertaken. No toxic effects were observed. In a phase 2 double-blind clinical trial of 67 patients with severe head trauma, which was completed in six major hospitals in Israel, the elevation of intracranial pressure above a threshold of 20 to $25 \mathrm{mmHg}$ was significantly attenuated in the HU-211-treated patients (63). A consistent trend toward better overall outcome, as determined by a standard scale (Glasgow outcome scale), was observed in the severe patient subgroup. This very encouraging clinical trial has made possible a large phase 3 clinical trial, which is now underway in Europe.

\section{CONCLUSIONS}

Cannabinoids are already in use for the enhancement of appetite in AIDS patients and for the prevention of nausea and vomiting caused by cancer chemotherapy. In the near future, cannabinoids may be approved to reduce the severity of the symptoms of MS. It is possible that CBD will be developed as a drug for the treatment of rheumatoid arthritis.

If the phase 3 clinical trials for neuroprotection with HU-211 are successful, this synthetic cannabinoid may be used for head injury and later possibly for the reduction of stroke damage.

\section{REFERENCES}

1. Mechoulam R. The pharmacohistory of Cannabis sativa. In: Mechoulam R, ed. Cannabinoids as Therapeutic Agents. Boca Raton: CRC Press, 1986:1-19.

2. Julien S. Substance anesthésique employée en Chine, dans le commencement du IIIe siècle de notre ère, pour paralyser momentanément la sensibilité. C R Hebd Seances Acad Sci 1849;28:195-8.

3. Li HL. The origin and use of cannabis in eastern Asia. In: Rubin V, ed. Cannabis and Culture. The Hague: Mouton, 1975:51-63.

4. Mechoulam R, Hanuš L, Fride E. Towards cannabinoid drugs revisited. Prog Med Chem 1998;35:199-243.

5. Hansen HS, Lauritzen L, Moesgaard B, Strand AM, Hansen HH. Formation of $\mathrm{N}$-acyl-posphatidylethanolamines and $\mathrm{N}$-acylethanolamines - proposed role in neurotoxicity. Biochem Pharmacol 1998;55:719-25.

6. Dewey WL. Cannabinoid pharmacology. Pharmacol Rev 1986;38:151-78.

7. Malfait AM, Gallily R, Sumariwalla PF, et al. The non-psychoactive cannabis constituent cannabidiol is an oral anti-arthritic therapeutic in murine collagen-induced arthritis. Proc Natl Acad Sci USA 2000;97:9561-6.

8. Thompson RC. A Dictionary of Assyrian Botany. London: The British Academy, 1949:200.

9. Abel EL. Marijuana, the First Twelve Thousand Years. New York: Plenum Press, 1980.

10. O'Shaugnessy WB. On the Cannabis indica or Indian hemp. Pharmacol J Trans 1843;2:594-5.

11. Reynolds JR. Therapeutic uses and toxic effects of Cannabis indica. Lancet 1890;i:637-8.

12. Gaoni Y, Mechoulam R. Isolation, structure and partial synthesis of an active constituent of hashish. J Am Chem Soc 1964;86:1646-7.

13. Mechoulam R, Ben-Shabat S. From gan-zi-gun-nu to anandamide and 2-arachidonoylglycerol: the ongoing story of cannabis. Nat Prod Rep 1999;16:131-43. 
14. Mechoulam R, Fride E, Di Marzo V. Endocannabinoids. Eur J Pharmacol 1998;359:1-18.

15. Devane WA, Dysarz FA, Johnson MR, Melvin LS, Howlett AC. Determination and characterization of a cannabinoid receptor in rat brain. Mol Pharmacol 1988;34:605-13.

16. Matsuda LA, Loliat SJ, Brownstein MJ, Young AC, Bonner TI. Structure of a cannabinoid receptor and functional expression of the cloned cDNA. Nature 1990;346:561-4.

17. Munro S, Thomas KL, Abu-Shaar M. Molecular characterization of a peripheral receptor for cannabinoids. Nature 1993;365:61-5.

18. Kaminski NE, Abood ME, Kessler FK, Martin BR, Schatz AR. Identification of a functionally relevant cannabinoid receptor on mouse spleen cells that is involved in cannabinoid-mediated immune modulation. Mol Pharmacol 1992;42:736-42.

19. Devane WA, Breuer A, Sheskin T, Järbe TUC, Eisen MS, Mechoulam R. A novel probe for the cannabinoid receptor. J Med Chem 1992;35:2065-9.

20. Devane WA, Hanuš L, Breuer A, et al. Isolation and structure of a brain constituent that binds to the cannabinoid receptor. Science 1992;258:1946-9.

21. Hanuš L, Gopher A, Almog S, Mechoulam R. Two new unsaturated fatty acid ethanolamides in brain that bind to the cannabinoid receptor. J Med Chem 1993;36:3032-4.

22. Schmid HHO, Schmid PC, Natarajan V. N-acylated glycerophospholipids and their derivatives. Prog Lipid Res 1990;29:1-43.

23. Axelrod J, Felder CC. Cannabinoid receptors and their endogenous agonist, anandamide. Neurochem Res 1998;23:575-81.

24. Piomelli D, Giuffrida A, Calignano A, Rodriguez-de-Fonseca F. The endocannabinoid system as a target for therapeutic drugs. Trends Pharmacol Sci 2000;21:218-24.

25. Mechoulam R, Ben-Shabat S, Hanuš L, et al. Identification of an endogenous 2-monoglyceride, present in canine gut, that binds to the cannabinoid receptors. Biochem Pharmacol 1995;50:83-90.

26. Sugiura T, Kondo S, Sukagawa A, et al. 2-Arachidonoylglycerol: A possible endogenous cannabinoid receptor ligand in brain. Biochem Biophys Res Commun 1995;215:89-97.

27. Ben-Shabat S, Fride E, Sheskin T, et al. An entourage effect: inactive endogenous fatty acid glycerol esters enhance 2-arachidonoyl-glycerol cannabinoid activity. Eur J Pharmacol 1998;353:23-31.

28. Di Marzo V, Deutsch DG. Biochemistry of the endogenous ligands of cannabinoid receptors. Neurobiol Dis 1998;5:386-404.

29. Mechoulam R, ed. Cannabinoids as Therapeutic Agents. Boca Raton: CRC Press, 1986

30. Archer RA, Stark P, Lemberger L. Nabilone. In: Mechoulam R, ed. Cannabinoids as Therapeutic Agents. Boca Raton: CRC Press, 1986:85-104.

31. Levitt M. Cannabinoids as antiemetics in cancer chemotherapy. In: Mechoulam R, ed. Cannabinoids as Therapeutic Agents. Boca Raton: CRC Press, 1986:71-84.

32. Feigenbaum JJ, Richmond SA, Weissman Y, Mechoulam R. Inhibition of cisplatin induced emesis in the pigeon by a non-psychotropic synthetic cannabinoid. Eur J Pharmacol 1989;169:159-65.

33. Fride E, Mechoulam R. Ontogenetic development of the response to anandamide and $\Delta 9$-tetrahydrocannabinol in mice. Brain Res Dev Brain Res 1996;95:131-4.

34. Abrahamov A, Abrahamov A, Mechoulam R. An efficient new cannabinoid antiemetic in pediatric oncology. Life Sci 1995;56:2097-102.

35. Beal JE, Olson, RLL, Morales JO, et al. Dronabinol as a treatment for anorexia associated with weight loss in patients with AIDS. J Pain Symptom Manage 1995;10:89-97.

36. Consroe P, Musty R, Rein J, Tillery W, Pertwee R. The percieved effects of smoked cannabis on patients with multiple sclerosis. Eur Neurol 1997;38:44-8.

37. Lyman WD, Sonett Jr, Brosnan CF, Elkin R, Bornstein MB. Delta-9-tetrahydrocannabinol - a novel treatment for experimental autoimmune encephalomyelitis. J Neuroimmunol 1989;23:73-81.

38. Wirguin I, Mechoulam R, Breuer A, Schezen E, Weidenfeld J, Brenner T. Suppression of experimental autoimmune encephalomyelitis by cannabinoids. Immunopharmacology 1994;28:209-14.
39. Baker D, Pryce G, Croxford JL, et al. Cannabinoids control spasticity and tremor in a multiple sclerosis model. Nature 2000;404:84-7.

40. Petro DJ, Ellenberger C Jr. Treatment of human spasticity with delta9-tetrahydrocannabinol. J Clin Pharmacol 1981;21:413S-6S.

41. Brenneisen R, Egli A, Elsohly MA, Henn V, Spiess Y. The effect of orally and rectally administered delta-9-tetrahydrocannabinol on spasticity: A pilot study with 2 patients. Int J Clin Pharmacol Ther 1996;34:446-52.

42. British Medical Association. Therapeutic uses of cannabis. Amsterdam: Harwood Academic Publishers, 1997.

43. Razdan RK. Structure-activity relationships in cannabinoids. Pharmacol Rev 1986;38:75-149.

44. Carlini EA, Leite JR, Tanhauser M, Berardi AC. Cannabidiol and Cannabis sativa extract protect mice and rats against convulsive agents. J Pharmacol 1973;25:664-5.

45. Consroe P. Brain cannabinoid systems as targets for the therapy of neurological disorders. Neurobiol Dis 1998;5:534-51.

46. Cunha JM, Carlini EA, Pereira AE, et al. Chronic administration of $\mathrm{CBD}$ to health volunteers and epileptic patients. Pharmacologia 1980;21:175-85.

47. Formukong EA, Evans AT, Evans FJ. Analgesic and antiinflammatory activity of constituents of Cannabis sativa L. Inflammation 1988;12:361-71.

48. Watzl B, Scuderi P, Watson RR. Marijuana components stimulate human peripheral blood mononuclear cell secretion of interferon-gamma and suppress interleukin-1 alpha in vitro. Int J Immunopharmacol 1991;13:1091-7.

49. Srivastava MD, Srivastava BI, Brouhard B. Delta-9tetrahydrocann-abinol and cannabidiol alter cytokine production by human immune cells. Immunopharmacology 1998;40:179-85.

50. Guimaraes FS, de Aguiar JC, Mechoulam R, Breuer A. Anxiolytic effect of cannabidiol derivatives in the elevated plus-maze. Gen Pharmacol 1994;25:161-4.

51. Zuardi AW, Cosme RA, Graeff FG, Guimaraes FS. Effects of ipsapirone and cannabidiol on human experimental anxiety. J Psychopharmacol 1993;7:82-8.

52. Zuardi AW, Shirakawa I, Finkelfarb E, Karniol I. Action of cannabidiol on the anxiety and other effects produced by delta-9-THC in normal subjects. Psychopharmacology 1982;76:245-50.

53. Agurell S, Carlsson S, Lindgreen JE, Ohlsson A, Gillespie H, Hollister L. Interactions of delta-1-tetrahydrocannabinol with cannabinol and cannabidiol following oral administration in man. Assay of cannabinol and cannabidiol by mass fragmentography. Experientia 1981;37:1090-2.

54. Leweke FM, Schneider U, Radwan M, Schmidt E, Emrich HM. Different effects of nabilone and cannabidiol on binocular depth inversion in man. Pharmacol Biochem Behav 2000;66:175-81.

55. Zuardi AW, Morais SL, Guimaraes FS, Mechoulam R. Antipsychotic effect of cannabidiol. J Clin Psychiatry 1995;56:485-6.

56. Mechoulam R, Feigenbaum JJ, Lander N, et al. Enantiomeric cannabinoids: stereospecificity of psychotropic activity. Experientia $1988 ; 44: 762-4$

57. Nadler V, Mechoulam R, Sokolovsky M. Blockade of Ca-45(2+) influx through the n-methyl-d-aspartate receptor-ion channel by the non-psychoactive cannabinoid HU-211. Brain Res 1993;622:79-85.

58. Eshhar N, Striem S, Biegon A. HU-211, a non-psychotropic cannabinoid, rescues cortical-neurons from excitatory amino-acid toxicity in culture. Neuroreport 1993;5:237-40.

59. Feigenbaum JJ, Bergmann F, Richmond SA, et al. A non-psychotropic cannabinoid acts as a functional N-methyl-D-asparate (NMDA) receptor blocker. Proc Natl Acad Sci USA 1989;86:9584-7.

60. Shohami E, Mechoulam R. Dexanabinol (HU-211): A nonpsychotropic cannabinoid with neuroprotective properties. Drug Dev Res 2000;50:211-5.

61. Beigon A, Bar-Joseph A. Development of HU-211 as a neuroprotectant for ischemic brain damage. Neurol Res 1995;17:275-80.

62. Leker RR, Shohami E, Abramsky O, Ovadia H. Dexanabinol: a novel neuroprotective drug in experimental focal cerebral ischemia. J Neurosci Res 1999;162:114-9.

63. Knoller N, Levi L, Israel Z, et al. Safety and outcome in a phase II clinical trial of dexanabinol in severe head trauma. Congress of Neurological Surgeons. Seattle, October 7, 1998. 


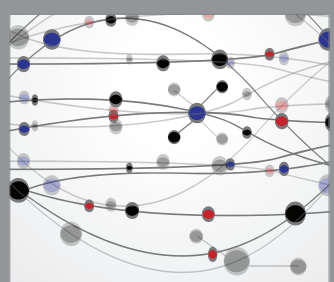

The Scientific World Journal
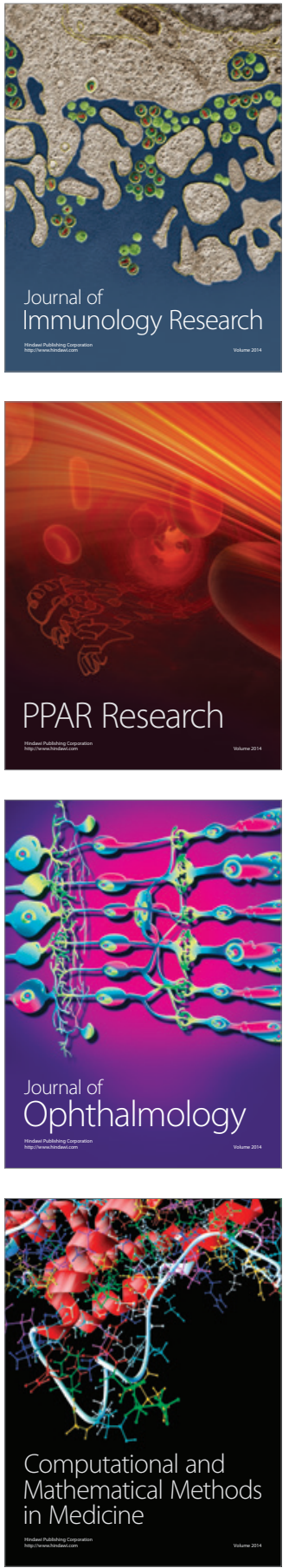

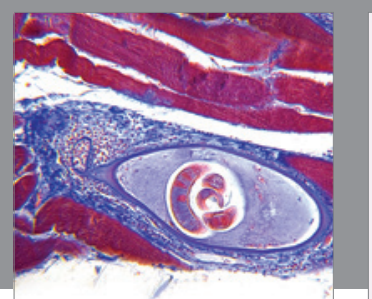

Gastroenterology Research and Practice

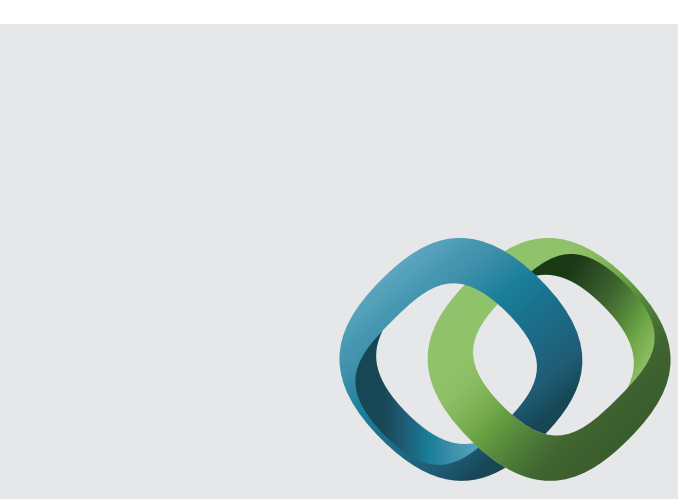

\section{Hindawi}

Submit your manuscripts at

http://www.hindawi.com
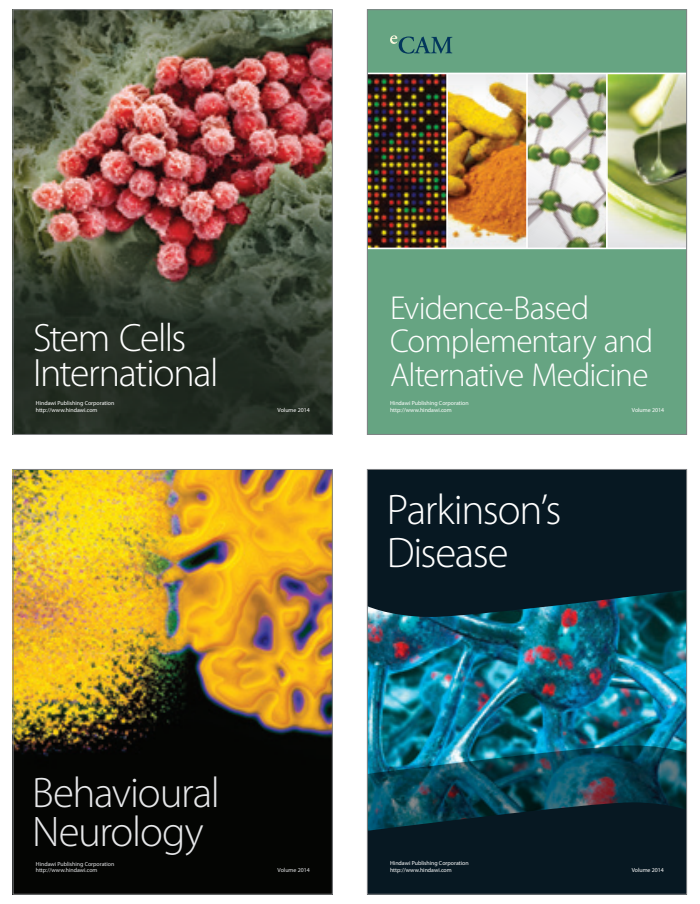
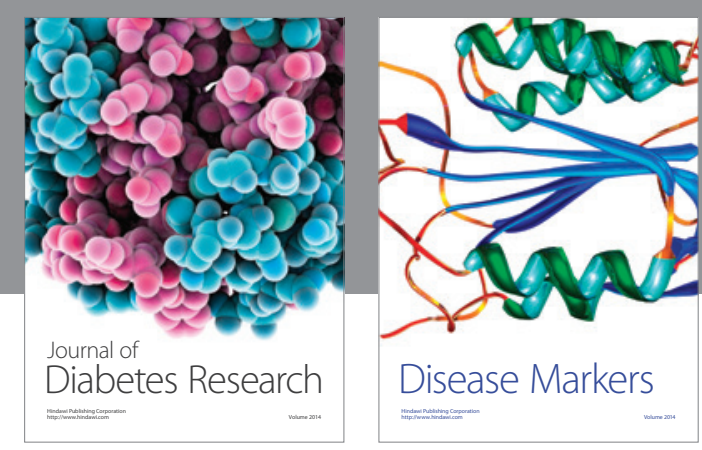

Disease Markers
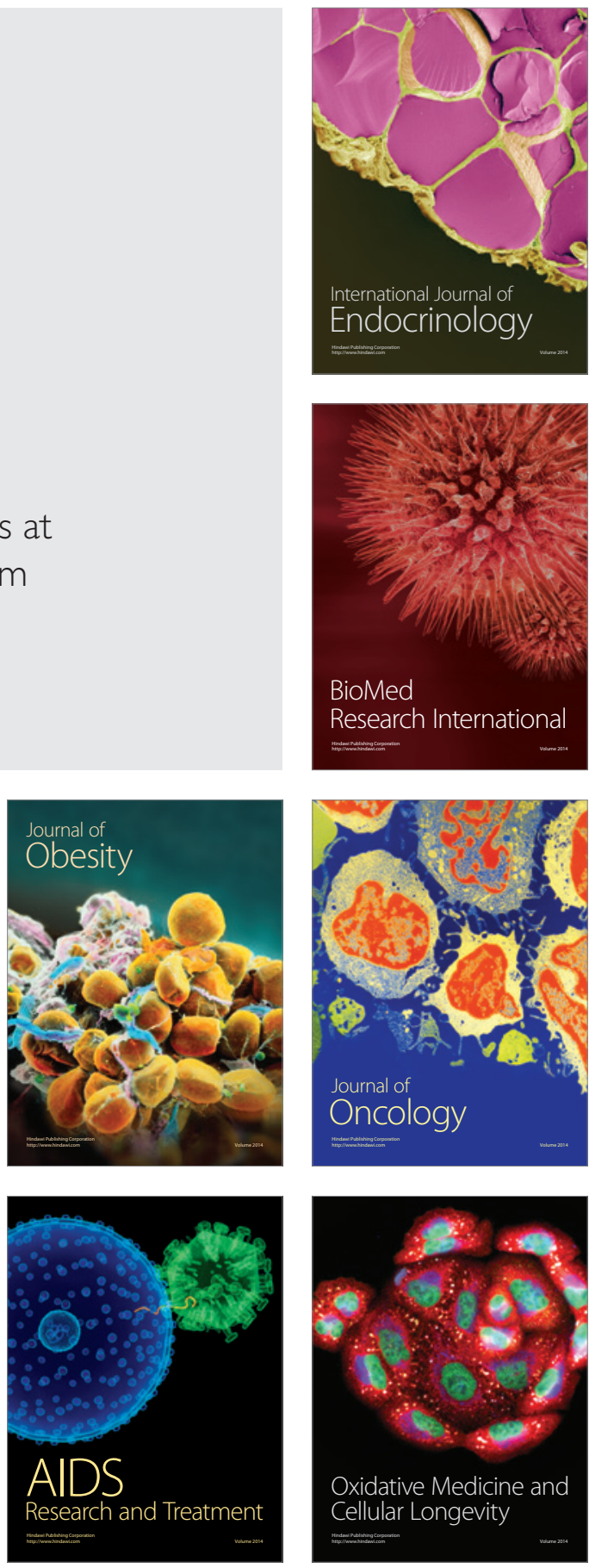